\title{
Peak bone mineral density in Vietnamese women
}

\author{
H. T. T. Nguyen • B. von Schoultz • D. M. T. Pham • \\ D. B. Nguyen • Q. H. Le • D. V. Nguyen • \\ A. L. Hirschberg • T. V. Nguyen
}

Received: 13 June 2007 / Accepted: 29 May 2008 / Published online: 14 February 2009

(C) The Author(s) 2009. This article is published with open access at Springerlink.com

\begin{abstract}
Summary This cross-sectional study showed that peak bone mineral density in Vietnamese women is comparable to that in Caucasian women; however, the prevalence of osteoporosis in post-menopausal Vietnamese women was slightly higher than in Caucasian women. The age of achieving peak bone mass in Vietnamese women was between 26 and 30 years.

Introduction While peak bone mass and its determinants have been well-documented in Caucasian populations, little has been studied in Asian populations. The present study was designed to estimate the peak bone mineral density (BMD), age of its attainment, and to examine the prevalence of osteoporosis in Vietnamese women aged 50+.

Methods The study was designed as a cross-sectional study with 328 women aged between 10 and 65 years (average age: 41) who were randomly selected from two districts around Hanoi city according to a stratified sampling scheme. BMD at the lumbar spine, femoral neck and total
\end{abstract}

H. T. T. Nguyen $(\bowtie) \cdot$ D. M. T. Pham

Department of Physiology, Hanoi Medical University,

1 Ton That Tung Street,

Dong Da Dist, Hanoi, Vietnam

e-mail: huong.nguyen@ki.se

D. B. Nguyen • Q. H. Le • D. V. Nguyen

National Cancer Hospital,

Hanoi, Vietnam

H. T. T. Nguyen • B. von Schoultz • A. L. Hirschberg Department of Woman and Child Health, Karolinska Institute, Stockholm, Sweden

T. V. Nguyen

Bone and Mineral Research Program,

Garvan Institute of Medical Research,

Sydney, Australia hip was measured by a DXA instrument (GE Lunar Prodigy, WI, USA). BMD was modeled as a cubic function of age, from which peak BMD and age at peak BMD were estimated. Bootstrap method was utilized to estimate the $95 \%$ confidence interval of peak BMD and age at peak BMD. From the peak BMD, T-score was calculated for each woman, and using the World Health Organization criteria, any woman with femoral neck BMD T-score $\leq-2.5$ was classified as having osteoporosis.

Results Peak BMD was estimated at $1.16 \mathrm{~g} / \mathrm{cm}^{2}$ (standard deviation [SD]: $0.13 \mathrm{~g} / \mathrm{cm}^{2}$ ) at the lumbar spine, $1.02 \mathrm{~g} / \mathrm{cm}^{2}$ (SD 0.12) at the total hip, and $0.94 \mathrm{~g} / \mathrm{cm}^{2}$ (SD 0.11) at the femoral neck. In the cubic polynomial model, the age at peak BMD was estimated to range between 27 and 29 years. The prevalence of osteoporosis among those aged between 50 and 65 years was $23 \%$. This prevalence was higher than in Chinese, Japanese, Korean and Caucasian populations. Conclusion These data suggest that although the peak BMD in Vietnamese women is comparable to, the prevalence of osteoporosis is higher than, in some other Asian and Caucasian women. It seems that osteoporosis is an important public health burden in Vietnam.

Keywords Peak BMD - Osteoporosis prevalence · Vietnamese women

\section{Introduction}

Osteoporosis and its consequence of fracture are recognized as an important global public health problem, because fracture is associated with increased mortality [1], concomitant morbidity, and reduced quality of life [2]. It is projected that approximately half of all hip fractures in the world occur in Asia [3, 4]. Despite the expected 
magnitude of the problem, the prevalence of and risk factors of osteoporosis in Asian countries are not well documented due to lack of epidemiologic data.

Osteoporosis is often considered as a consequence of industrialization, because the incidence of osteoporotic fractures is higher in industrialized countries than in developing countries [4]. Furthermore, within a country, the incidence of fractures is higher in urban communities than in rural communities [5-8]. Therefore, study of osteoporosis prevalence in emerging developing countries may provide useful information on the evolution of the disease.

Vietnam is a developing country with a population of 84 million. After decades of wars and poverty, the country has been embarking on a market economy with a rapid urbanization being taken place in the entire country. Although osteoporosis is increasingly recognized as a major public health concern in Vietnam, there is currently a lack of documentation of the prevalence of osteoporosis and data on the peak bone mass in the population is not available. In a previous study based on quantitative ultrasound measurements (QUS), it was estimated that $20 \%$ of postmenopausal women had low bone mass (subjects whose T-score were $\leq-2.5 \mathrm{SD}$ ) [9]. However, QUS is not an ideal means to assess skeletal health; therefore, the prevalence of osteoporosis in the Vietnamese population remains unknown.

The present study was designed to estimate the peak bone mineral density, age of its attainment and the prevalence of osteoporosis in Vietnamese women aged 50+.

\section{Study design and methods}

\section{Study design}

The study was designed as a cross-sectional investigation with multistage sampling scheme. The study was approved by the ethics committee of Hanoi Medical University. The setting was in Hanoi, the capital of Vietnam. Two districts (Dong Da and Soc Son) in Hanoi were selected for the study site. In each district, 4 communes were randomly selected, and then a full list of subjects in each commune was obtained from the local government authority which served as the sampling frame. The lists were then sorted by age 10-year group. For each age group, a total of 100 women were randomly selected by a computergenerated numbers for screening interview. We assumed that the peak BMD was $1 \mathrm{~g} / \mathrm{cm}^{2}$ with standard deviation being $0.1 \mathrm{~g} / \mathrm{cm}^{2}$, then the required sample size was about 120-150 women aged between 10 and 49 years. The targeted sample was therefore 400 women. Among the 400 women randomly selected, 373 women (response rate of
93\%) agreed to participate in the study. However, after excluding women who did not meet the study entry criteria, only 168 women were ultimately included in the study. A further random sample of women aged between 50 and 65 from the same communes were invited to participate in the study for estimating the prevalence of osteoporosis. In this sampling scheme, women aged 50 and 65 were randomly selected from all communes. Initially 386 women agreed to participate in the study; however, only 160 women met all the inclusion and exclusion criteria. In total, 343 women aged between 10 and 65 were eligible for participating in the study.

Women were excluded from the study if they had conditions that are deemed to affect bone metabolism such as chronic diseases (dysfunctions of liver, gut, kidney, endocrine system, respiratory or cardiovascular system, auto-immune diseases and cancer), or use of medications, or more than one month in bed, or premature menopause or hysterectomy/oophorectomy, or history of fracture.

\section{Measurements}

BMD was measured at the lumbar spine (LS), left and right femoral neck $(\mathrm{FN})$ and total hip $(\mathrm{TH})$ in all qualified subjects. The measurements were done with a dual energy X-ray absortiometry (DXA) densitometer (GE Lunar Prodigy advance). The precision error $(\% \mathrm{CV})$ in our laboratory was $1.75 \%$ for lumbar spine and $1.5 \%$ for hips. The machine was standardized by standard phantom every time before measurement. In this analysis, BMD at the lumbar spine was estimated from L2 to L4. Femoral neck and total hip BMD used in the analysis was estimated from the right side.

Anthropometrical parameters including weight, standing height, sitting height, leg length, chest, waist, and hip circumferences were collected. Body weight was measured by using electronic balance with indoor clothing without shoes. Height was determined without shoes on a portable stadiometer with mandible plane parallel to the floor.

\section{Data analysis}

In order to estimate peak BMD, a series of polynomial regression models (up to the third degree) were fitted to femoral neck, total hip and lumbar spine BMD as a function of age. In these models, the expected value of BMD at each skeletal site was expressed as follows: $B M D=\alpha+\beta_{1}($ age $)+\beta_{2}(\text { age })^{2}+\beta_{3}(\text { age })^{3}$, where $\alpha$ is the intercept, $\beta_{1}, \beta_{2}$, and $\beta_{3}$ are regression parameters to be estimated from the observed data. Reduced models (i.e., quadratic and linear models) were also considered, and the "final" model was chosen based on the Akaike Information Criterion (AIC) [10]. Peak BMD and age that reached peak 
BMD were estimated from the final model. The $95 \%$ confidence interval of peak BMD and aged of peak BMD were determined by the bootstrap (resampling) method [11]. In this method of analysis, 1000 samples, each with 300 individuals, were drawn from the original sample with replacement, the cubic equation was fitted to each sample, and the $95 \%$ confidence of the 1000 peak BMD and age of peak BMD were then determined. The analysis was performed with $\mathrm{R}$ environment [12] and the Design library [13].

From the peak BMD, T-score, which is the number of standard deviations from the peak BMD, were calculated for each individual in the study sample. The prevalence of osteoporosis was estimated for women aged 50+. An individual was classified as having osteoporosis if her femoral neck BMD T-score was equal or lower than -2.5 [14]. Standard error and 95\% confidence interval of the prevalence were estimated based on the assumption of binomial distribution.

\section{Results}

In total, 328 women aged between 10 and 65 years enrolled in the study, whereas 15 subjects for various reasons were unable to participate. Out of these 328 women, 49\% were aged 50 years or older. Mean values for weight and height of the different age groups (Table 1) were similar to the normal range as reported for Vietnamese women [15]. BMD measurement at each site was significantly and independently correlated with height $(\mathrm{r}=0.42 ; \mathrm{p}<0.0001)$ and weight $(\mathrm{r}=0.46 ; \mathrm{p}<0.0001)$. Lumbar spine BMD was significantly correlated with total hip BMD $(r=0.75 ; \mathrm{p}<0.0001)$, which was in turn correlated with femoral neck BMD $(r=0.94$; $\mathrm{p}<0.0001)$.

As expected, cross-sectionally, BMD at the lumbar spine, total hip and femoral neck rapidly increased during the adolescence and then gradually declined after the age of 40 (Figure 1). The equations that best described this trend was a third degree polynomial function of age as follows:

$$
\begin{aligned}
& \text { Lumber spine BMD }=0.1236+0.0855 \times \text { Age } \\
& \begin{aligned}
-0.0022 \times \mathrm{Age}^{2}+0.0000155 \times \mathrm{Age}^{3} \\
\text { Total hip BMD }=0.3582+0.0532 \times \mathrm{Age}-0.0013 \times \mathrm{Age}^{2} \\
+0.00009 \times \mathrm{Age}^{3}
\end{aligned}
\end{aligned}
$$

Femoral neck BMD $=0.3353+0.0508 \times$ Age

$$
-0.0013 \times \mathrm{Age}^{2}+0.000009 \times \mathrm{Age}^{3}
$$

These equations accounted for $47 \%, 30 \%$ and $36 \%$ of the variation at the lumbar spine, total hip, and femoral neck BMD, respectively. The regression coefficients shown above suggest that the increase in BMD during the adolescence was greater at the lumbar spine than at the hip $\left(0.085\right.$ vs $\left.0.05 \mathrm{~g} / \mathrm{cm}^{2}\right)$; however, the subsequent decrease in BMD was also greater at the lumbar spine than at the hip $\left(0.0022\right.$ vs $\left.0.0013 \mathrm{~g} / \mathrm{cm}^{2}\right)$. For any given site, BMD among those aged 50-65 years was reduced by between $20 \%$ and $28 \%$ as compared to the peak BMD level.

Based on the bootstrap analysis, peak BMD and the age when peak BMD reached were estimated (Table 2). According to these results, the peak BMD values for the lumbar spine and total hip were $1.16 \mathrm{~g} / \mathrm{cm}^{2}$ (SD 0.13) and $1.02 \mathrm{~g} / \mathrm{cm}^{2}$ (SD 0.12) respectively. The age at peak BMD was around 29 years. The corresponding value for peak femoral neck BMD was slightly lower: $0.94 \mathrm{~g} / \mathrm{cm}^{2}$ (SD 0.11 ) and the age at peak BMD was around 28 years.

Using the estimated peak BMD and standard deviation, femoral neck T-scores were calculated for each women, and the prevalence of osteoporosis (i.e., T-scores $\leq-2.5$ ) [14] was estimated and shown in Table 3. Approximately $23 \%$ of women aged 50-65 years had osteoporosis at the femoral neck. The prevalence increased with advancing age such that among those aged between 50 and 59 it was estimated

\begin{tabular}{|c|c|c|c|c|c|c|}
\hline Age group & $<20(\mathrm{n}=58)$ & $20-29(n=36)$ & $30-39(n=37)$ & $40-49(n=37)$ & $50-59(n=136)$ & $60-65(n=24)$ \\
\hline Age (yr) & $13.8 \pm 2.8$ & $23.8 \pm 2.9$ & $34.1 \pm 2.4$ & $32.6 \pm 2.8$ & $55.4 \pm 2.5$ & $60.8 \pm 1.4$ \\
\hline Weight (kg) & $38.8 \pm 9.2$ & $46.1 \pm 4.9$ & $48.8 \pm 5.8$ & $50.6 \pm 7.2$ & $44.4 \pm 6.7$ & $44.3 \pm 8.4$ \\
\hline Height $(\mathrm{cm})$ & $146.6 \pm 9.2$ & $152.1 \pm 4.8$ & $152.1 \pm 5.6$ & $152.6 \pm 5.8$ & $148.7 \pm 4.8$ & $148.9 \pm 4.1$ \\
\hline BMI $\left(\mathrm{kg} / \mathrm{cm}^{2}\right)$ & $17.8 \pm 2.8$ & $20.0 \pm 1.8$ & $21.1 \pm 2.2$ & $21.7 \pm 2.5$ & $20.1 \pm 2.6$ & $20.0 \pm 4.2$ \\
\hline \multicolumn{7}{|c|}{ BMD measurement $\left(\mathrm{g} / \mathrm{cm}^{2}\right)$} \\
\hline Lumbar spine & $0.93 \pm 0.16$ & $1.11 \pm 0.12$ & $1.12 \pm 0.17$ & $1.08 \pm 0.15$ & $0.85 \pm 0.12$ & $0.80 \pm 0.13$ \\
\hline Total hip & $0.87 \pm 0.15$ & $1.00 \pm 0.10$ & $0.98 \pm 0.12$ & $1.00 \pm 0.13$ & $0.84 \pm 0.11$ & $0.78 \pm 0.08$ \\
\hline Femoral neck & $0.81 \pm 0.13$ & $0.9 \pm 0.11$ & $0.89 \pm 0.12$ & $0.89 \pm 0.12$ & $0.73 \pm 0.10$ & $0.69 \pm 0.06$ \\
\hline
\end{tabular}
at $21 \%$ and increased to $33 \%$ in those aged $60-65$ years or above. The calculation for osteoporosis at the lumbar spine was $49 \%$ for women aged $50-69$.

Table 1 Characteristics of study subjects

*Values shown are mean and standard deviation 

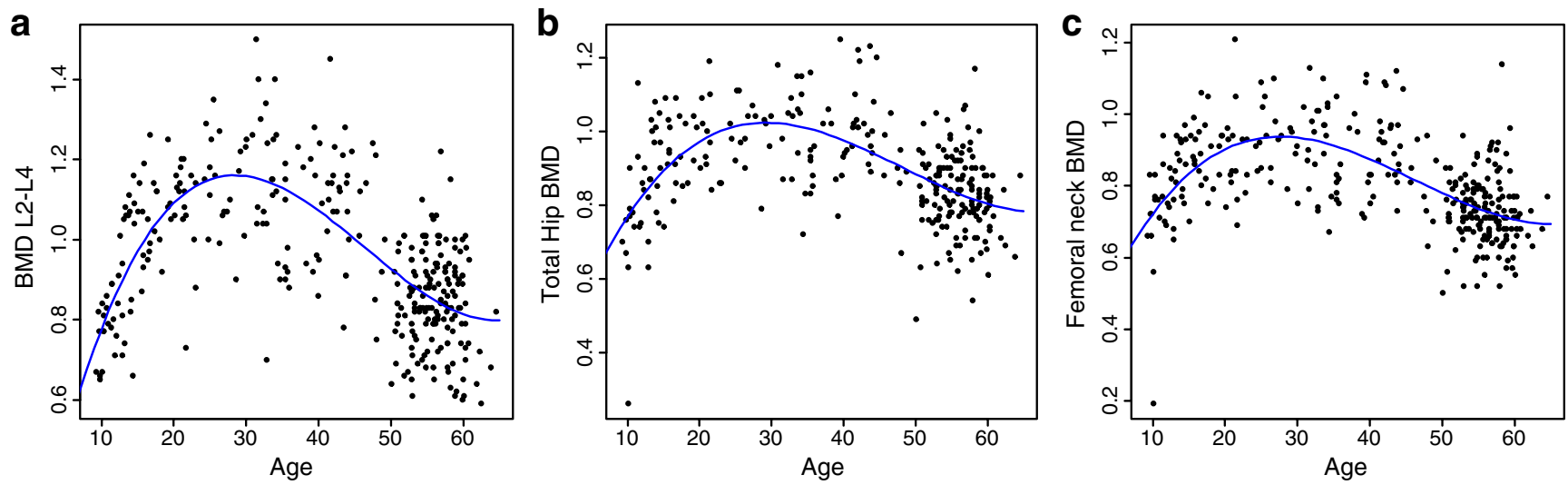

Fig. 1 Relationship between age and lumbar spine BMD (panel A), total hip BMD (B), and femoral neck BMD (C)

There was a discordance in the diagnosis of osteoporosis based on femoral neck and total hip T-scores. When the total hip BMD T-score was used, the prevalence was $26 \%$. However, when either femoral neck or total hip BMD was used, the prevalence increased to $33.7 \%$. Although the proportion of concordance in the diagnosis between the two BMD sites was $80 \%$, the kappa statistic was $0.49(95 \%$ confidence interval: $0.34-0.65$, data not shown) which was statistically significantly different from $0(\mathrm{p}<0.0001)$.

\section{Discussion}

BMD is an important predictor of future fracture [16-18] and individuals with osteoporosis are at increased risk [18]. It has been shown that $65 \%$ of individuals with osteoporosis will sustain a fracture within the next 10 years [19] or 15 years [20]. The present study suggests that approximately a quarter of Vietnamese women aged $50+$ are at high risk of fracture. Thus, it seems that osteoporosis represents an important burden of public health in Vietnam.

It is interesting to note that using the same densitometer (GE Lunar) the peak BMD at the femoral neck in Vietnamese women was comparable to that of Korean $[21,22]$ and slightly higher than in Japanese [21], Chinese [23] and Indonesian women [24] (Table 4). However, given the sampling variation and the lack of calibration between densitometers the differences among Asian populations seem insignificant. The present estimated prevalence is also equivalent to that of in American Caucasian women [25,
26] even though the latter was based on Hologic DXA. Some of the differences in prevalence could be partially due to the difference in bone densitometry technologies. However, the effect of measurement technology is likely to be small because the prevalence was determined from BMD T-scores, and T-scores are standardized to mean and standard deviation obtained from each densitometer and each population. Notwithstanding, the finding rather suggests that the diagnosis of osteoporosis can be based on a global reference data base.

However, when the Third National Health and Nutrition Examination Survey (NHANES III) reference data were used, the prevalence of osteoporosis in Vietnamese women was estimated to $60 \%, 31 \%$, and $21 \%$ at the lumbar spine, total hip, and femoral neck, respectively. These estimates were slightly higher than those based on the Vietnamesespecific reference data, because largely of the difference in standard deviations between the two populations.

The present data suggest that Vietnamese women may achieve their peak BMD at a later age (between 28 and 29 years) than Caucasian women among whom the peak BMD was reached between 20-25 years [25, 26]. It is not possible to determine the underlying factors to explain this apparent difference. However, it is well-known that Asian girls tend to have a later menarche (average age of 13 years) than Caucasian girls (12 years). It is possible that nutritional factors and lower levels of estrogen and other sex steroids contribute to the difference. It is also noted that after reaching its peak, lumbar spine BMD starts declining. While this trend was also observed in other populations [27,

Table 2 Estimate of peak BMD, standard deviation and age of peak BMD

\begin{tabular}{llll}
\hline BMD site & Peak BMD and 95\% CI & SD of peak BMD & Age of peak BMD and 95\% CI \\
\hline Lumbar spine BMD & $1.16(1.13-1.19)$ & 0.13 & $28.5(27.5-29.6)$ \\
Total hip BMD & $1.02(1.00-1.05)$ & 0.12 & $29.3(27.8-31.1)$ \\
Femoral neck BMD & $0.94(0.92-0.96)$ & 0.11 & $27.7(26.4-29.0)$ \\
\hline
\end{tabular}


Table 3 Prevalence (\%) of osteoporosis by site of BMD measurement

\begin{tabular}{llll}
\hline BMD site & Age group & & \\
\cline { 2 - 4 } & $\begin{array}{l}50 \text { and above } \\
(\mathrm{n}=160)\end{array}$ & $\begin{array}{l}50-59 \\
(\mathrm{n}=136)\end{array}$ & $\begin{array}{l}60-65 \\
(\mathrm{n}=24)\end{array}$ \\
\hline $\begin{array}{l}\text { Femoral neck } \\
\text { Total hip }\end{array}$ & 23.1 & 21.3 & 33.3 \\
\hline
\end{tabular}

28] but not all [29], the reason for this decline is not known. It is possible that this decline reflects a secular trend among segments of the premenopausal population. However, this issue could not be addressed in this study as there is a lack of prospective data (Table 5).

It is likely that the prevalence of osteoporosis was underestimated in this study, because there were no women aged above 65 years in the study. Even so, the prevalence (between $23 \%$ and $26 \%$ ) is slightly higher than in Australian (21\%) [30] and American (20\%) [31] but lower than in Thai (29\%) [32] and Hong Kong women [17]. However, the prevalence of osteoporosis in the present study appears to be substantially higher than Chinese $(10 \%$,$) [33], Japanese (17\%) [34], Korean (10\%) [21] and$ Indonesian women (15\%) [24]. It is interesting to note that even though the peak bone mass of Vietnamese women was found comparable to that of Caucasian and other Asian girls, the prevalence of osteoporosis among women aged 50-65 was still higher than in many other countries. One possible explanation could be that of cohort effect: women aged 50+ were born and grew up during many years of war, when the country's economy was in great hardship and many women suffered from malnutrition which accumulatively resulted in low BMD. In contrast, the younger cohort aged between 20 and 30 years was born and raised after the independence in 1975, during which economic and nutritional conditions have significantly been better than that during the war years.

Table 4 Comparison of young adult bone mineral density

\begin{tabular}{llll}
\hline Population & \multicolumn{3}{l}{ Peak BMD (mean and SD) } \\
\cline { 2 - 4 } & Lumbar spine & Total hip & Femoral neck \\
\hline Vietnamese & $1.16 \pm 0.13$ & $1.02 \pm 0.12$ & $0.94 \pm 0.11$ \\
Indonesian $^{1}$ & $1.10 \pm 0.12$ & $0.93 \pm 0.11$ & $0.91 \pm 0.12$ \\
Korean $^{2}$ & $1.15 \pm 0.12$ & $0.98 \pm 0.11$ & $0.94 \pm 0.11$ \\
Japanese $^{2}$ & $1.11 \pm 0.12$ & $0.93 \pm 0.12$ & $0.90 \pm 0.12$ \\
Chinese $^{2}$ & $1.11 \pm 0.12$ & $0.98 \pm 0.13$ & $0.93 \pm 0.12$ \\
Australian $^{3}$ & $1.23 \pm 0.13$ & $1.05 \pm 0.13$ & $1.02 \pm 0.13$ \\
White American $^{2}$ & $1.18 \pm 0.12$ & $1.00 \pm 0.12$ & $0.98 \pm 0.12$ \\
\hline
\end{tabular}

\footnotetext{
${ }^{1}$ Tirtarahardja G, et al [24]

${ }^{2}$ Yang SO, et al [21]

${ }^{3}$ Henry MJ, et al [26]
}

Table 5 Comparison of prevalence of osteoporosis among women aged $50+$ years

\begin{tabular}{|c|c|c|}
\hline \multirow[t]{2}{*}{ Population } & \multicolumn{2}{|c|}{ Prevalence $(\%)$ of osteoporosis } \\
\hline & Total hip & Femoral neck \\
\hline Vietnamese (this study) ${ }^{*}$ & 25.6 & 23.1 \\
\hline Vietnamese American ${ }^{1}$ & - & 37.0 \\
\hline Thai $^{2}$ & - & 29.5 \\
\hline Indonesian $^{3}$ & $\sim 10.0$ & $\sim 15.0$ \\
\hline Chinese $^{4}$ & 19.8 & 10.1 \\
\hline Hong Kong & $15.6^{5}$ & $49.6^{6}$ \\
\hline Japanese $^{7}$ & 14.6 & 17.0 \\
\hline Korean ${ }^{8}$ & $\sim 8.0$ & $\sim 10.0$ \\
\hline Australian $^{9}$ & - & 21.4 \\
\hline U.S White ${ }^{10}$ & 17.0 & 20.0 \\
\hline
\end{tabular}

${ }^{1}$ Marquez M, et al [35]

${ }^{2}$ Limpaphayom KK, et al [32]

${ }^{3}$ Tirtarahardja G, et al [24]

${ }^{4} \mathrm{Wu} \mathrm{XP}$, et al [33]

${ }^{5}$ Lynn HS et al [23]

${ }^{6} \mathrm{Ho}$ SC, et al. [36]

${ }^{7}$ Iki $\mathrm{M}$ et al [34]

${ }^{8}$ Yang SO, et al [21]

${ }^{9}$ Henry MJ, et al [30]

${ }^{10}$ Looker A, et al [31]

*Note that the estimate in this study was limited within the age range of 50 and 65 years.

The present results should be interpreted in relation to some strengths and weaknesses. The sample was randomly drawn from the general population after careful screening, which should support its representativity and external validity. The sample size was statistically adequate to estimate a prevalence of osteoporosis as $30 \%$ with a marginal error of $3 \%$. The use of DXA technology with reliable measurement of BMD is also a strength of this study. However, the design was crosssectional and therefore the estimate of peak BMD and age of peak BMD could be subject to uncontrolled bias. Ideally, these values should be determined in a representative cohort which should be followed from 5 years to 30 years of age. However, it is unlikely that such a study is feasible; therefore, a cross-sectional study is an alternative design. The estimate of osteoporosis prevalence in post-menopausal women was based on a rather small sample size, particularly among those aged 60-65 $(\mathrm{n}=24)$, which could result in an increased sampling error. Because the maximum age of participants in this study was 65 , the estimate of prevalence was likely underestimate.

In summary, this study has, for the first time, provided an estimation of peak BMD in Vietnamese women. The peak bone mass in this study was found comparable to global reference data but the prevalence of osteoporosis was higher than in some other Asian and Caucasian populations. It seems that osteoporosis is an important public health burden in Vietnam. 
Acknowledgments We would like to extend our thanks to Sida/ SAREC for providing research fund and scholarship award for the first author to conduct the study; Hanoi Medical University, especially staff in the Department of Physiology and all members in FSH group, for the constant support and help in the data collection; Karolinska Institute (Sweden) and Garvan Institute (Australia) for hospitality. We especially thank Dr. Nguyen Dinh Nguyen of the Garvan Institute for help in the data analysis; Dr. Tran Van Thuan of the National Cancer Hospital (Vietnam) for his continuous support of the study. We appreciate the support from Dong Da and Soc Son District Health Care Centers, and all the women who have participated in the study.

Open Access This article is distributed under the terms of the Creative Commons Attribution Noncommercial License which permits any noncommercial use, distribution, and reproduction in any medium, provided the original author(s) and source are credited.

\section{References}

1. Center JR, Nguyen TV, Schneider D, Sambrook PN, Eisman JA (1999) Mortality after all major types of osteoporotic fracture in men and women: an observational study. Lancet 353:878-882

2. Randell AG, Nguyen TV, Bhalerao N, Silverman SL, Sambrook PN, Eisman JA (2000) Deterioration in quality of life following hip fracture: a prospective study. Osteoporos Int 11:460-466

3. Cooper C, Campion G, Melton LJ 3rd (1992) Hip fractures in the elderly: a world-wide projection. Osteoporos Int 2:285-289

4. Lau EM, Lee JK, Suriwongpaisal P, Saw SM, Das De S, Khir A, Sambrook P (2001) The incidence of hip fracture in four Asian countries: the Asian Osteoporosis Study (AOS). Osteoporos Int 12:239-243

5. Sanders KM, Nicholson GC, Ugoni AM, Seeman E, Pasco JA, Kotowicz MA (2002) Fracture rates lower in rural than urban communities: the Geelong Osteoporosis Study. J Epidemiol Community Health 56:466-470

6. Chevalley T, Herrmann FR, Delmi M, Stern R, Hoffmeyer P, Rapin CH, Rizzoli R (2002) Evaluation of the age-adjusted incidence of hip fractures between urban and rural areas: the difference is not related to the prevalence of institutions for the elderly. Osteoporos Int 13:113-118

7. Mannius S, Mellstrom D, Oden A, Rundgren A, Zetterberg C (1987) Incidence of hip fracture in western Sweden 1974-1982. Comparison of rural and urban populations. Acta Orthop Scand 58:38-42

8. Madhok R, Melton LJ 3rd, Atkinson EJ, O'Fallon WM, Lewallen DG (1993) Urban vs rural increase in hip fracture incidence. Age and sex of 901 cases $1980-89$ in Olmsted County, U.S.A.. Acta Orthop Scand 64:543-548

9. Thuy VT, Chau TT, Cong ND, De DV, Nguyen TV (2003) Assessment of low bone mass in Vietnamese: comparison of QUS calcaneal ultrasonometer and data-derived T-scores. J Bone Miner Metab 21:114-119

10. Akaike H (1973) Information theory and an extension of the maximum likelihood principal. Proc 2nd Int Symp Information Theory, Suppl Problems of Control and Information Theory 267281.

11. Efron B, Tibshirani R (1986) Bootstrap methods for standard errors, confidence intervals, and other measures of statistical accuracy. Stat Sci 1:54-77

12. Feskanich D, Willett W, Colditz G (2002) Walking and leisuretime activity and risk of hip fracture in postmenopausal women. JAMA 288:2300-2306

13. Harrell FE Jr, Lee KL, Mark DB (1996) Multivariable prognostic models: issues in developing models, evaluating assumptions and adequacy, and measuring and reducing errors. Stat Med 15:361-387
14. Kanis JA, Gluer CC (2000) An update on the diagnosis and assessment of osteoporosis with densitometry. Committee of Scientific Advisors, International Osteoporosis Foundation. Osteoporos Int 11:192-202

15. Le TN (2003) Reference range of biological values in Vietnamese popualation decade 90s. Medicine Publishing Hourse: 14-20.

16. Nguyen T, Sambrook P, Kelly P, Jones G, Lord S, Freund J, Eisman J (1993) Prediction of osteoporotic fractures by postural instability and bone density. Bmj 307:1111-1115

17. Cummings SR, Cawthon PM, Ensrud KE, Cauley JA, Fink HA, Orwoll ES (2006) BMD and risk of hip and nonvertebral fractures in older men: a prospective study and comparison with older women. J Bone Miner Res 21:1550-1556

18. Marshall D, Johnell O, Wedel H (1996) Meta-analysis of how well measures of bone mineral density predict occurrence of osteoporotic fractures. BMJ 312:1254-1259

19. Kung AW, Lee KK, Ho AK, Tang G, Luk KD (2007) Ten-Year Risk of Osteoporotic Fractures in Postmenopausal Chinese Women According to Clinical Risk Factors and BMD T Scores: A Prospective Study. J Bone Miner Res.

20. Nguyen ND, Ahlborg HG, Center JR, Eisman JA, Nguyen TV (2007) Residual lifetime risk of fractures in women and men. J Bone Miner Res 22:781-788

21. Yang SO, Kim D, Sohn M, Kang Y, Park L, Shin C, Kim M, Kim EN, Barden HS (2006) Normative study on bone mineral density in a Korean women using DXA. Abstract SU084.

22. Xiong DH, Shen H, Zhao LJ, Xiao P, Yang TL, Guo Y, Wang W, Guo YF, Liu YJ, Recker RR, Deng HW (2006) Robust and comprehensive analysis of 20 osteoporosis candidate genes by very high-density single-nucleotide polymorphism screen among 405 white nuclear families identified significant association and gene-gene interaction. J Bone Miner Res 21:1678-1695

23. Lynn HS, Lau EM, Au B, Leung PC (2005) Bone mineral density reference norms for Hong Kong Chinese. Osteoporos Int 16:1663-1668

24. Tirtarahardja G, Setyohadi B, Weynand LS, Zhu Q (2006) Bone mineral density reference values Indonesian men and women. Abstract SA105

25. Nguyen TV, Maynard LM, Towne B, Roche AF, Wisemandle W, Li J, Guo SS, Chumlea WC, Siervogel RM (2001) Sex differences in bone mass acquisition during growth: the Fels Longitudinal Study. J Clin Densitom 4:147-157

26. Henry MJ, Pasco JA, Pocock NA, Nicholson GC, Kotowicz MA (2004) Reference ranges for bone densitometers adopted Australia-wide: Geelong osteoporosis study. Australas Radiol 48:473475

27. Wu XP, Liao EY, Huang G, Dai RC, Zhang H (2003) A comparison study of the reference curves of bone mineral density at different skeletal sites in native Chinese, Japanese, and American Caucasian women. Calcif Tissue Int 73:122-132

28. Kudlacek S, Schneider B, Peterlik M, Leb G, Klaushofer K, Weber K, Woloszczuk W, Willvonseder R (2003) Normative data of bone mineral density in an unselected adult Austrian population. Eur J Clin Invest 33:332-339

29. Matkovic V, Jelic T, Wardlaw GM, Ilich JZ, Goel PK, Wright JK, Andon MB, Smith KT, Heaney RP (1994) Timing of peak bone mass in Caucasian females and its implication for the prevention of osteoporosis. Inference from a cross-sectional model. J Clin Invest 93:799-808

30. Pasco JA, Sanders KM, Henry MJ, Nicholson GC, Seeman E, Kotowicz MA (2000) Calcium intakes among Australian women: Geelong Osteoporosis Study. Aust N Z J Med 30:21-27

31. Looker AC, Orwoll ES, Johnston CC Jr, Lindsay RL, Wahner HW, Dunn WL, Calvo MS, Harris TB, Heyse SP (1997) Prevalence of low femoral bone density in older U.S. adults from NHANES III. J Bone Miner Res 12:1761-1768 
32. Limpaphayom KK, Taechakraichana N, Jaisamrarn U, Bunyavejchevin S, Chaikittisilpa S, Poshyachinda M, Taechamahachai C, Havanond P, Onthuam Y, Lumbiganon P, Kamolratanakul P (2001) Prevalence of osteopenia and osteoporosis in Thai women. Menopause 8:65-69

33. McNutt LA, Wu C, Xue X, Hafner JP (2003) Estimating the relative risk in cohort studies and clinical trials of common outcomes. Am J Epidemiol 157:940-943

34. Kaneki M, Hedges SJ, Hosoi T, Fujiwara S, Lyons A, Crean SJ, Ishida N, Nakagawa M, Takechi M, Sano Y, Mizuno Y, Hoshino S,
Miyao M, Inoue S, Horiki K, Shiraki M, Ouchi Y, Orimo H (2001) Japanese fermented soybean food as the major determinant of the large geographic difference in circulating levels of vitamin K2: possible implications for hip-fracture risk. Nutrition 17:315-321

35. Melton IL, Marquez MA, Achenbach SJ, Tefferi A, O'Connor MK, O'Fallon WM, Riggs BL (2002) Variations in bone density among persons of African heritage. Osteoporos Int 13:551-559

36. Ho SC, Lau EM, Woo J, Sham A, Chan KM, Lee S, Leung PC (1999) The prevalence of osteoporosis in the Hong Kong Chinese female population. Maturitas 32:171-178 